\title{
Morphological changes in peri-prostatic sympathetic ganglion cells in aging males
}

\author{
LEA RATH-WOLFSON $^{1}$, ASAF SHVERO ${ }^{2}$, GOLAN BUBIS ${ }^{3}$, GALINA BUZAVEROV ${ }^{4}$, \\ ALIZA ZEIDMAN $^{4}$, EDWARD RAM $^{5}$ and RUMELIA KOREN ${ }^{1}$
}

\author{
${ }^{1}$ Department of Pathology, Hasharon Hospital, Rabin Medical Center; ${ }^{2}$ Department of Urology, \\ Sheba Medical Center, Affiliated with Sackler Faculty of Medicine, Tel Aviv University, Petach Tikva, Tel Aviv 6997801, \\ Israel; ${ }^{3}$ St. George's University of London, University of Nicosia Medical School, 2408 Nicosia, Cyprus; \\ Departments of ${ }^{4}$ Internal Medicine 'B' and ${ }^{5}$ Surgery 'A', Hasharon Hospital, Rabin Medical Center, Affiliated \\ with Sackler Faculty of Medicine, Tel Aviv University, Petach Tikva, Tel Aviv 6997801, Israel
}

Received November 21, 2016; Accepted February 15, 2017

DOI: $10.3892 /$ mco.2017.1196

\begin{abstract}
A significant part of morbidity in elderly male patients involves the pelvic organs and their autonomic neural regulation. The aim of the current study was to report the histopathological changes in the peri-prostatic ganglia in elderly males. The sympathetic ganglia from 36 prostatectomy specimens, 26 due to carcinoma of the prostate and 10 prostates from total cystectomies for transitional cell carcinoma, were examined. The age range was 54-88 years. A total of 5,075 ganglion cells were counted in all the specimens. Pathological changes were identified in 1,696 neuron cells as follows: Neuronophagia in 746 neuron cells, neuron cell vacuolization (330 cells), satellite cells vacuolization ( 423 cells), cell pyknosis (148 cells) and nageotte nodules ( 49 cells). A number of these changes increased with age. All the changes were more marked in the peri-prostatic ganglion cells of patients with prostatic adenocarcinoma compared with those with benign prostate hyperplasia, which may be due to local environmental changes associated with the presence of malignancy.
\end{abstract}

\section{Introduction}

Much of the morbidity in elderly men involves organs of the pelvic region. These include lower urinary tract symptoms, incontinence and erectile dysfunction. The functions of these organs are regulated by the regional autonomic ganglia, primarily the pelvic ganglia. The pathological changes that produce autonomic dysfunction in human aging are largely unknown; however, in experimental animal models specific pathological

Correspondence to: Mr. Golan Bubis, St. George's University of London, University of Nicosia Medical School, 93 Agiou Nikolau Street, 2408 Nicosia, Cyprus

E-mail: bubisgolan@gmail.com

Key words: pelvic sympathetic ganglia, aging, neuronophagy, nageotte nodules changes have been identified in selected sympathetic ganglia (1) Alterations in the pelvic ganglia and their function may also be modified by nutritional and environmental factors (2).

Sympathetic ganglia are infrequently biopsied or removed surgically, so the majority of the human studies have been performed using autopsy material $(3,4)$. Therefore, these studies have unavoidable histological artifacts and inherent difficulty in retrospectively establishing the normality of sympathetic ganglions cells. In order to avoid these difficulties, the present study examined pelvic sympathetic ganglia derived from surgical pathology. Tissue obtained from total prostatectomy and radical cystectomy and prostatectomy were handled immediately following excision in order to avoid the artifacts of autolysis found in post mortem material. The aim of the present study was to examine the histopathological changes in the pelvic ganglia, in the region surrounding the prostate, in surgical specimens in benign and malignant disease.

\section{Patients and methods}

Patients. Two groups of patients were selected for this study, and each group underwent prostatectomy in the Urology Department (Hsharon Hospital, Petach Tikva, Israel) between the March 1993 and November 2000. The patients received either radical prostatectomy due to carcinoma of the prostate (group A) or radical cystectomy and prostatectomy, due to urothelial carcinoma of the urinary bladder (group B).

Group A. Group A consisted of 26 cases of prostatectomy performed due to prostatic carcinoma. The age of the patients ranged between 54-74 years (mean, 62.7). Eight patients were known to be smokers and one was a heavy alcohol user. In total, 16 patients (51.6\%) suffered from hypertension, which was controlled by therapy. Five patients (16\%) had ischemic heart disease and $3(9.7 \%)$ had a history of stroke. The follow up period ranged between 6 months and 216 months (mean, 156 months).

Group B. Group B consisted of 10 cases of radical cystectomy due to urothelial carcinoma of the bladder. In all the cases there 
was no invasion of the urothelial carcinoma into the prostate. The histopathological examination of all prostate tissue in this group revealed benign prostatic hyperplasia $(\mathrm{BPH})$. The age of the patients ranged between 56-88 years (mean, 69.3 years). Four $(28.5 \%)$ patients suffered from ischemic heart disease, 6 (42.8) had controlled hypertension, 7 (50\%) were known to be smokers. 1 (7\%) had colon cancer and $1(7 \%)$ suffered from lung cancer and underwent irradiation therapy. The follow-up period ranged between 11 and 144 months (mean, 69.2 months).

Pathological examination. All specimens were sent to the pathology department as fresh tissues. The external surface was stained with Indian ink to mark the surgical margins. Total sampling of the prostates was performed (5) by sectioning the prostate tissues (thickness, 2-3 mm), which were formalin-fixed, paraffin-embedded and stained with hematoxylin and eosin (H\&E). Slices of the posterior areas of the prostate were examined, the sympathetic ganglia were identified and counted, and the histopathological changes were determined.

Statistical analysis. Data were analyzed using two-way analysis of variance. The group of prostates with adenocarcinoma compared with those with BPH as the first between subjects factor and age as the second factor. In order to further explore the main effects, a post hoc Tukey test was performed when comparing age or Student $t$-test when comparing between the groups A and B. To examine the association between variables, Pearson's correlation analysis was conducted. In order to overcome small sample bias, bootstrapping analysis was performed. All tests were calculated as two-tailed with SPSS 21.0 (IBM SPSS, Armonk, NY, USA). Results are presented as mean \pm standard error of the mean. $\mathrm{P}<0.05$ was considered to indicate a statistically significant difference.

\section{Results}

Group A, adenocarcinoma of the prostate. All patients suffered Gleason's grade 6 primary adenocarcinoma of the prostate (6). The percentage of involvement of the prostate tissue by carcinoma ranged between 10 and 75\% (mean, 34\%). In four $(12.9 \%)$ patients, the surgical margins were involved, while in the rest the margins were free of tumor. In one $(3.2 \%)$ of these tissue samples, peri-neural invasion was present. Lymphatic invasion was identified in one (3.2\%) patient, and three patients $(9.7 \%)$ had lymphatic and vascular invasion of the tumor. In total, 3 patients $(9.7 \%)$ were in stage T1B, 4 patients $(13 \%)$ were at stage T2A, 18 patients $(58 \%)$ were stage T2B, 2 patients $(6.4 \%)$ were stage T3A, 3 patients $(9.7 \%)$ were stage $\mathrm{T} 3 \mathrm{C}$ and one patient (3.2\%) was stage T4A (7). PSA levels in the blood prior to surgery ranged between 5.3 and $44 \mathrm{ng} / \mathrm{ml}$ (mean, $11.35 \mathrm{ng} / \mathrm{ml}$ ). In the majority of laboratories a PSA serum level of $4 \mathrm{ng} / \mathrm{ml}$ is reported as the cut-off between normal and abnormal (6). PSA levels in the blood following surgery ranged between 0 and $4.2 \mathrm{ng} / \mathrm{ml}$ (mean, $0.23 \mathrm{ng} / \mathrm{ml}$ ). Two $(6.4 \%)$ of these patients suffered from local recurrence of the tumors and one (3.2\%) developed distant metastasis to the bone. At the end of this study 12 patients $(38.7 \%)$ had succumbed to the disease.
Group A histopathological changes. In group A 157 ganglions were identified, of which 91 were found in the right posterior region, 6 in the mid posterior region and 60 in the left posterior region with a total count of 3,835 ganglion cells (Table I). On histological examination the prevalent changes were as follows: Neuron vacuolization in 283 ganglion cells, pyknosis in 135 ganglion cells, satellite cell vacuolization in 351 ganglion cells, neuronophagia was in 634 ganglion cells and nageotte nodules in 40 ganglion cells. Pyknosis is a condensation and reduction in the size of cells and nuclei (Fig. 1A). During neuronophagy, activated microglial cells surround and ingest a dead neuron (Fig. 1B). In satellite cell vacuolization, cytoplasmic vacuolization is visible in the satellite cells (Fig. 1C). Nageotte nodules are compact areas of satellite cell proliferation (Fig. 1D). In neuron vacuolization there are clear vacuoles in the cytoplasm of the ganglion cells.

Group B, radical cystectomy and prostatectomy. Pathological examination of the urinary bladder revealed low-grade urothelial carcinoma in 2 patients and high-grade urothelial carcinoma in 8 patients. The stage of the disease (8) was A in 2 patients, $\mathrm{B}$ in 3 patients and $\mathrm{C}$ in 5 patients. The prostate exhibited BPH in all patients in group B. Of the 10 tissues in this group, 28 ganglion were identified, of which 16 were found in the right posterior region and 12 in the left posterior region with a total count of 1,240 ganglion cells.

Group B histopathological changes. The histopathological examination of the ganglion cells revealed: Neuron vacuolization in 47 ganglion cells, pyknosis in 13 ganglion cells, satellite cell vacuolization in 72 ganglion cells, neuronophagia in 112 ganglion cells and 9 nageotte nodules (Table I).

Statistical analysis. Two way ANOVA reveled significant differences in neuron vacuolization between the ganglion cells in the prostatic carcinoma group compared with those with $\mathrm{BPH}\left[\mathrm{F}\left({ }_{1,29}\right)=4.602, \mathrm{P}<0.05\right]$. This difference was found to be significant only between ages 50-59 $(\mathrm{P}<0.05)$. Pyknosis and neuronophagia revealed significant differences in the ganglion cells of the prostatic carcinoma group compared with those with $\mathrm{BPH}\left[\mathrm{F}\left({ }_{1,28}\right)=4.185, \mathrm{P}<0.05\right]$ and $\left.\left[\mathrm{F}_{1,28}\right)=4.469, \mathrm{P}<0.05\right]$ accordingly. However, no significant difference was found between age groups $\left.\left[\mathrm{F}_{2,28}\right)<1\right]$. Age was significantly correlated with increase in satellite cell vacuolization $\left(R_{P}=0.349\right.$, $\mathrm{P}<0.044)$ in the patients with prostate adenocarcinoma. No significant differences according to age were identified within the BPH group. A tendency toward significance was found between age and the presence of nageotte nodules in the peri-prostatic ganglion cells $\left(\mathrm{R}_{\mathrm{P}}=0.316, \mathrm{P}=0.062\right)$ among patients diagnosed with prostate adenocarcinoma. No significant differences were found within the BPH group according to age and the presence of nageotte nodules.

\section{Discussion}

The present study identified several changes in the peri-prostatic ganglion cells. These consisted of neuron vacuolization, pyknosis, satellite vacuolization, neuronophagia and nageotte nodules. All these findings were statistically significant other than the nageotte nodules, which exhibited a tendency toward 
Table I. The histopathological changes in sympathetic ganglion cells in adenocarcinoma and BPH prostate tissues, according to patient age.

No. of neurons

\begin{tabular}{|c|c|c|c|c|c|c|c|}
\hline $\begin{array}{l}\text { Age of } \\
\text { patients }\end{array}$ & $\mathrm{N}$ & $\begin{array}{l}\text { Total no. } \\
\text { of neurons }\end{array}$ & $\begin{array}{c}\text { Neuron } \\
\text { vacuolization }\end{array}$ & Pyknosis & $\begin{array}{c}\text { Satellite } \\
\text { vacuolization }\end{array}$ & Neuronophagy & $\begin{array}{c}\text { Nageotte } \\
\text { nodules }\end{array}$ \\
\hline \multicolumn{8}{|l|}{ Group A } \\
\hline $50-59$ & 4 & 453 & 61 & 25 & 50 & 62 & 2 \\
\hline $60-69$ & 17 & 2,425 & 148 & 95 & 171 & 402 & 29 \\
\hline $70-89$ & 5 & 957 & 74 & 15 & 130 & 170 & 9 \\
\hline \multicolumn{8}{|l|}{ Group B } \\
\hline $50-59$ & 2 & 149 & 3 & 0 & 10 & 11 & 2 \\
\hline $60-69$ & 6 & 1,038 & 33 & 9 & 55 & 92 & 6 \\
\hline $70-89$ & 2 & 53 & 11 & 4 & 7 & 9 & 1 \\
\hline
\end{tabular}
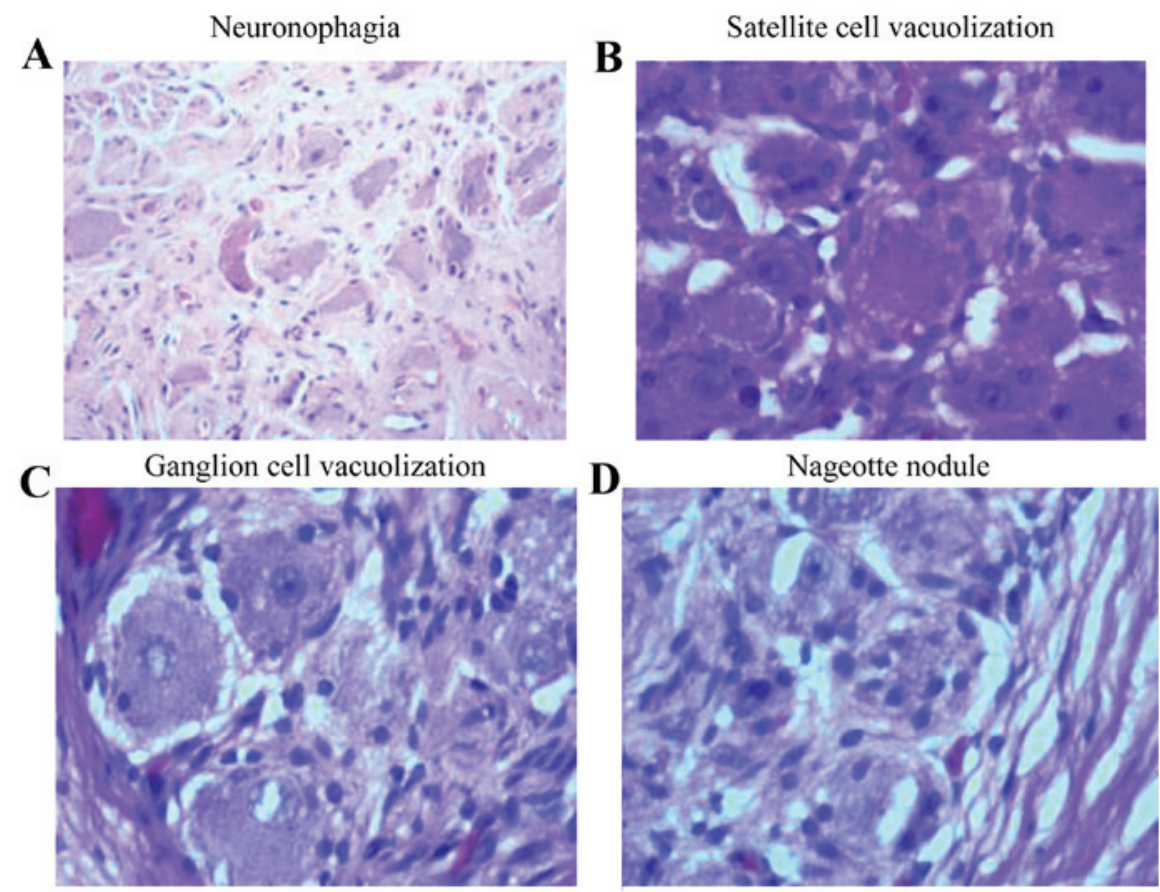

Figure 1. Various histopathological changes in the sympathetic ganglion cells. (A) Pyknosis, a condensation and reduction in the size of cells and nucleus. (B) Satellite cell vacuolization. Lipofuscin is present in the ganglion cells. (C) Neuronophagia, activated microglial cells surround and ingest a dead neuron. (D) Nageotte nodules, compact areas of satellite cell proliferation. Staining, hematoxylin and eosin; magnification, x10.

significance. Significant differences in neuron vacuolization in ganglion cells between the peri-prostatic tissue with adenocarcinoma of the prostate and patients with BPH were only identified in the patients aged 50-59 years. In all the other groups this difference had no statistical significance. This trend may be explained by the fact that all the cases examined were $>50$ years, when degenerative changes start. All these changes were more marked in the peri-prostatic ganglion cells of group A (prostatic adenocarcinoma), which may be due to environmental changes associated with the local presence of malignancy. A significant portion of morbidity in elderly males involves the pelvic organs and their autonomic neural regulation. These include lower urinary tract symptoms, incontinence and impairment of bowel activity and motility.
All these functions are regulated by the regional autonomic ganglia, primarily the pelvic ganglia, and may be caused by the degenerative changes described.

Age-associated degenerative changes have been extensively reported in the literature, mainly in rats. Warburton and Santer (1) revealed that with aging a definite decrease in the number of sympathetic, but not parasympathetic, nerve cells innervating the bladder, lower ureters and urethra occurs. In the prostate itself the variations are primarily related to a lack of balance in sex hormones (9). Investigations of the changes in the sympathetic ganglion cells of rats induced by citral, which simulates sex hormone functions, were performed by Golomb et al (10). These authors found changes that were detected only in the older rat group (age, 18 months). These 
changes included accumulation of lipofuscin pigment in the ganglion cells, local aggregation of satellite cells nodules of nageotte and neuronal vacuolar degeneration (10). The effects of X-irradiation on ganglion cells of the lower back in rats were investigated by Masurovsky et al (11). In the first days, a sharp degeneration in the satellite cells was noted and later sequestration, vacuolization and autolysis were detected. All these changes were possibly linked to metabolic and membrane permeability (11). Acquired immunodeficiency syndrome-associated changes were evaluated by Burdo et al (12) through examination of the dorsal root ganglia of CD8-depleted simian immunodeficiency virus-infected rhesus macaques. The authors identified satellitosis, the presence of nageotte nodules, neuronophagy as well as increased numbers of CD68+ macrophages and abundant viral replication.

Kuntz (13) noted that age and environment affect the sympathetic ganglia. This previous study was performed on autopsy material of 50 patients aged 6-71 years old. The changes included hyalinization of the cytoplasm, hydropic enlargement or edema of ganglion cells, vacuolization of the cytoplasm, neuro-fibrillary changes and destruction of the cytoplasm by phagocytic cells. These changes appeared at 30-35 years and increased with age (13).

The effects of Acrolein on various cells including the sympathetic ganglia were examined by Liu-Snyder et al (14). They found cell death was induced by Acrolein $12 \mathrm{~h}$ after its application. There are very few studies on human surgical material. Hannani et al (15) found a statistically significant increase in the proportion of myenteric ganglia with cavities with increasing age. In the present study the sympathetic ganglia in the peripheral-posterior zone of the prostate were examined in surgical specimens obtained from total prostatectomy and total cystectomy. The following histological changes were found: Neuronophagia, neuron vacuolization, satellite vacuolization, pyknosis and nageotte nodule formation. Certain histological changes were significantly associated with age.

Previous studies have examined the influence of diabetes on the nervous system. Histological changes in the dorsal root and sympathetic trunk were identified (16). These included degeneration of ganglion cells, a decrease in their number and the formation of nageotte nodules in a patient with fulminant type 1 diabetes mellitus (16). Schmidt et al (2) performed quantitative studies on a series of adult autopsied diabetic and non-diabetic patients of various ages, demonstrating that neuron-axonal dystrophy increased with age in patients with diabetes, and males were more severely affected than females. A decrease in the number of neurons, primarily in the lumbar area, accompanied by satellite cell proliferation in patients with diabetes has been demonstrated in a number of studies (17-20). In 1909, Gomez and Pike (21) published data regarding the histopathological changes in neurons in anemia. To the best of our knowledge, this previous research was the first controlled study on this subject and definitively the first review of the literature. These authors reported the appearance of vacuoles in the cytoplasm of the cells in prolonged anemia. In contagious disease, Fratkin et al (22) reported the appearance of nodules of nageotte and lymphocytic aggregation in the presence of the West Nile virus. Nageotte nodules and mononuclear accumulation in the sympathetic ganglion cells in Guillen-Barre syndrome were identified by Patel et al (23).
In conclusion, in the present study, morphological changes in the sympathetic ganglia were identified in surgical specimens obtained from total prostatectomy and total cystectomy in elderly males. There were statistical differences between the changes in the two groups. All changes were more marked in the ganglion cells of prostatic adenocarcinoma compared with $\mathrm{BPH}$, which may be due to environmental changes occurring due to the local presence of malignancy. Certain changes increased with patient age. To the best of our knowledge, there are no studies in the literature on the pelvic sympathetic ganglia in human surgical material. The number of cases in the present study is limited and all the patients were elderly, therefore larger scale studies may be required to obtain more significant conclusions.

\section{Acknowledgements}

The authors would like to thank Professor Abramovici Armand (deceased), Department of Pathology, Sackler Faculty of Medicine, Tel Aviv University, Tel Aviv for his help in performing the present study.

\section{References}

1. Warburton AL and Santer RM: Sympathetic and sensory innervation of the urinary tract in young adult and aged rats: A semi-quantitative histochemical and immunohistochemical study. Histochem J 26: 127-133, 1994.

2. Schmidt RE, Plurad SB, Parvin CA and Roth KA: Effect of diabetes and aging on human sympathetic autonomic ganglia. Am J Pathol 143: 143-153, 1993.

3. Schmidt RE, Chae HY, Parvin CA and Roth KA: Neuroaxonal dystrophy in aging human sympathetic ganglia. Am J Pathol 136: 1327-1338, 1990.

4. Schmidt RE: Neuropathology of human sympathetic autonomic ganglia. Microsc Res Tech 35: 107-121, 1996.

5. Koren R, Gur U, Lask D, Livne MP, Shvero A, Neumann G and Rath-Wolfson L: Histopathological findings in the prostatic urethra evaluated by a new technique for processing radical prostatectomy specimens. Con Med 5: 8-16, 2010.

6. Robbins and Cotran. Pathologic basis of disease. 9th edition, Saunders, pp988, 2015.

7. Mohler JL, Armstrong AJ, Bahnson RR, D'Amico AV, Davis BJ, Eastham JA, Enke CA, Farrington TA, Higano CS, Horwitz EM, et al: Prostate cancer, version 1.2016. J Natl Compr Canc Netw 14: 19-30, 2016.

8. Cheng L, Montironi R, Davidson DD and Lopez-Beltran A: Staging and reporting of urothelial carcinoma of the urinary bladder. Mod Pathol 22 (Suppl 2): S70-S95, 2009.

9. Keast JR and Saunders RJ: Testosterone has potent, selective effects on the morphology of pelvic autonomic neurons which control the bladder, lower bowel and internal reproductive organs of the male rat. Neuroscience 85: 543-556, 1998.

10. Golomb E, Scolnik M, Koren R, Servadio C, Sandbank U and Abramovici A: Effects of senescence and citral on neuronal vacuolar degeneration in rat pelvic ganglia. Neurotoxicology 22: 73-77, 2001.

11. Masurovsky EB, Bunge MB and Bunge RP: Cytological studies of organotypic cultures of rat dorsal root ganglia following $\mathrm{X}$-irradiation in vitro. I. Changes in neurons and satellite cells. J Cell Biol 32: 467-496, 1967.

12. Burdo TH, Orzechowski K, Knight HL, Miller AD and Williams K: Dorsal root ganglia damage in SIV-infected rhesus macaques: An animal model of HIV-induced sensory neuropathy. Am J Pathol 180: 1362-1369, 2012.

13. Kuntz A: Histological variations in autonomic ganglia and ganglion cells associated with age and disease. Am J Pathol 14: 783-796, 1938.

14. Liu-Snyder P, McNally H, Shi R and Borgens RB: Acrolein-mediated mechanisms of neuronal death. J Neurosci Res 84: 209-218, 2006.

15. Hanani M, Fellig Y, Udassin R and Freund HR: Age-related changes in the morphology of the myenteric plexus of the human colon. Auton Neurosci 113: 71-78, 2004. 
16. Makino M, Hiwatashi D, Minemura K and Kawaguchi K: Autonomic and sensory ganglionopathy occurring in a patient with fulminant type 1 diabetes mellitus. Pathol Int 66: 102-107, 2016.

17. Dolman CL: The morbid anatomy of diabetic neuropathy. Neurology 13: 135-142, 1963

18. Greenbaum D, Richardson PC, Salmon MV and Urich $\mathrm{H}$ : Pathological observations on six cases of diabetic neuropathy. Brain 87: 201-214, 1964.

19. Olsson Y, Säve-Söderbergh J, Sourander P and Angervall L: A patho-anatomical study of the central and peripheral nervous system in diabetes of early onset and long duration. Pathol Eur 3: 62-79, 1968.
20. Russell JW, Sullivan KA, Windebank AJ, Herrmann DN and Feldman EL: Neurons undergo apoptosis in animal and cell culture models of diabetes. Neurobiol Dis 6: 347-363, 1999.

21. Gomez L and Pike FH: The histological changes in nerve cells due to total temporary anemia of the central nervous system. J Exp Med 11: 257-265, 1909.

22. Fratkin JD, Leis AA, Stokic DS, Slavinski SA and Geiss RW: Spinal cord neuropathology in human west nile virus infection. Arch Pathol Lab Med 128: 533-537, 2004.

23. Patel MB, Goyal SK, Punnam SR, Pandya K, Khetarpal V and Thakur RK: Guillain-Barré Syndrome with asystole requiring permanent pacemaker: A case report. J Med Case Rep 3: 5, 2009. 